Fundamental studies of chemical vapor depoxition diamond growth processess

R. W. Shaw, W. B. Whitten, and J. M. Ramsey

Analytical Chemistry Division

\author{
L. Heatherly \\ Metals and Ceramics Division \\ Oak Ridge National Laboratory \\ Oak Ridge TN 37831-6142
}

CONF-9107115--10

DE9] 015324

\begin{abstract}
We are developing laser spectroscopic techniques to foster a fundamental understanding of diam:ond film growth by hot filament chemical vapor deposition (CVD). Several spectroscopic techniques are under investigation to identify intermediate species present in the bulk reactor volume, the thin active volume immediately above the growing film, and the actual growing surface. Such a cemprehensive examination of the overall deposition process is necessary hecause a combination of gas phase and surface chemistry is probably operating. Resonantly enhanced multiphoton ionization (REMPI) techniques have been emphasized. A growih reactor that permits through-the-substrate gas sampling for REMPl/time-of-flight mass spectroscopy has been developed.
\end{abstract}

\title{
2. BACKGROUND
}

Little is known at the molecular level about the details of the chemical and physical mechanisms involved in CVD film growth processes. Most of the investigations of film growth processes to date have involved Edisonian studies; that is, operating parameters were varied and the quality of the material grown under these various conditions determined. The problem with this approach is that a real understanding of the material growth process is not achieved. This optimization approach may not examine the most important parameter required for the growth of a quality material. The real goal is to learn how to control the growth process for desirable film properties, not to optimize a given experiment.

Clearly small molecules (i.e., hydrocarbon fragments -neutrals and ions) play a role in diamond CVD, as does atomic hydrogen. The latter selectively etches and removes graphitic carbon that forms during the deposition. Ion or electron bombardment of the surface resulting in further molecular decomposition and lattice cross-linking may also be important.

The spectroscopic techniques described herein promote a chemical understanding of diamond growth by providing methods capable of measuring important growth species and determining their concentration gradients. Intermediate species present in the bulk reactor volume, the thin active volume immediately above the growing film, and the actual growing surface must be measured. Such a comprehensive examination of the overall deposition process is necessary because a combination of gas phase and surface chemistry is probably operating.

\section{RESULTS AND DISCUSSION}

A diamond film growth reacior was assembled, employing an O-ring sealed quartz cylinder (76 mm diameter) as a replaceable reactor vessel. Access to the interior of the reactor is via a high vacuum flange that also provides a gas inlet port and electrical and thermocouple feedthroughs. The quartz envelope serves as optical access to the substrate and was designed for convenient replacement or cleaning when dark wall coatings develop over time. The filament 
is a linear coil of $0.5 \mathrm{~mm}$ diameter tungsten wire that is carburized in $\mathrm{CH} / \mathrm{H}_{3}$ before a substrate is introduced. It is placed approxumately $5 \mathrm{~mm}$ from the substrate, which lies on the nat bollom of the quartz cylinder; the filament cemperature is medsured us'ng an oplkal pyrometer. A platunum-wired alumina substrate heater provides Joule heal independent of the filament to adjust the substrate temperature. Reactant gas now rate and reactor pressure are under active control using mass flow controllers and a pump throlle valve.

Films on single crystal silicon were successfully grown by decomposing $1 \%$ methane in hydrogen on a tungsten carbide filament heated to about $1950^{\circ} \mathrm{C}$. SEM images of the resulting films show a 10 micron typical grain size, with $\{111\}$ and $\{100\}$ exposed facets.

\subsection{Bulk gases}

The bulk reactor gas is probably the easiest (although not necessarily trivial) region to investigate. Techniques that allow three dimensional species and temperature mapping of the volume are desirabie. Many different reactant gases have served as the carbon source for reported diamond film growth processes; the distribution of molecular fragments can be expected to be dependent on the particular carbon source and on the activation proress employed (hot filament, RF discharge, etc.).

Detection of atomic hydrogen was demonstrated in the reactor under diamond growth conditions (40 torr, $1 \%$ methane in hydrogen, 50 SCCM flowrate) using $3+1$ resonance enhanced multiphoton ionization (REMPI) spectroscopy at $365 \mathrm{~nm}$. A spectral scan is shown in Figure 1. The output from a 10 pps Nd:YAG-pumped R6G dye laser was mixed with the pump laser fundamental wavelength to create the excitation light; pulse energies of $2 \mathrm{~mJ}$ were thus obtained. A travelling wave geometry ${ }^{\text {L2 }}$ was employed, and a platinum wire, situated between the reactor filament and a molybdenum substrate, was uscd 10 collect the pholo-charge. The substrate was negatively biased by 150 volts to suppress collection of electrons from the filament.

Three $304.7 \mathrm{~nm}$ photons reach the hydrogen $2 \mathrm{P}$ level from the 1s ground state. The line in Figure 1 represents ionization driven by absorption of third harmonic vacuum ultraviolet light generated in the medium ${ }^{2}$ and is at slightly highe energy than the true $1 \mathrm{~S}-2 \mathrm{P}$ resonance due 10 phase matching considerations. Addition of a retroreflecting mirro 10 create standing wave excltation should permit ionization via the resonant process which is known to be more

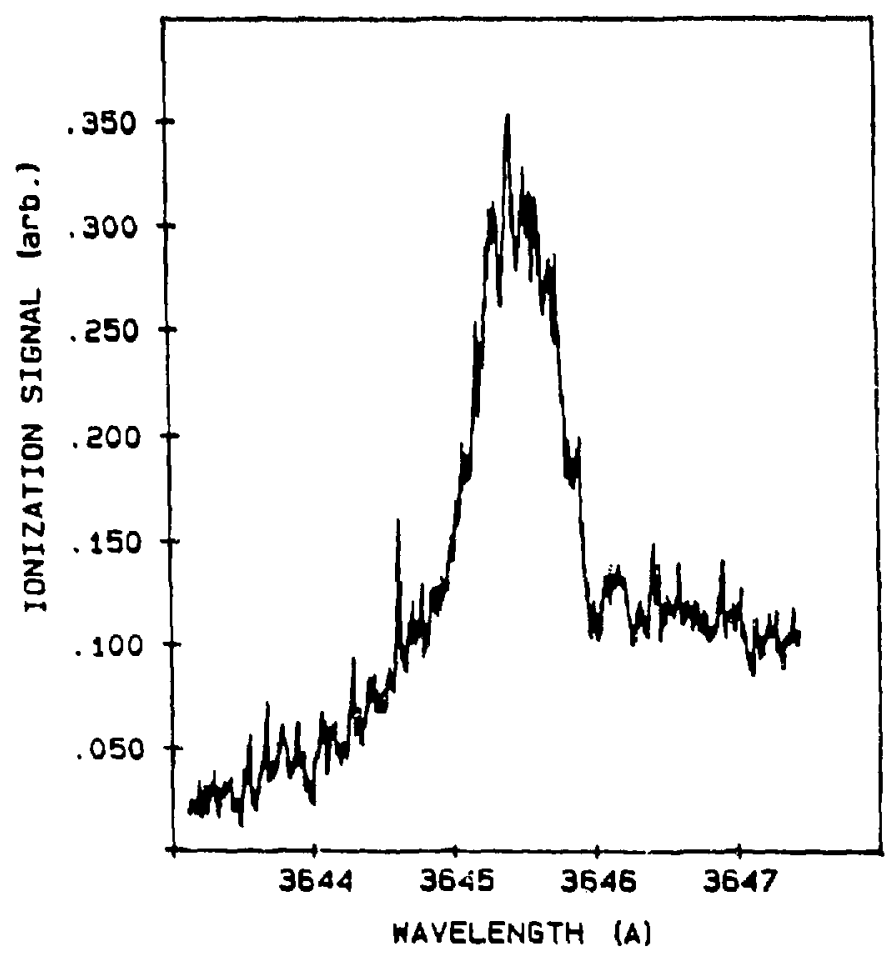

Figure 1. Spectra: scan of hydrogen atom $3+1$ REMPI. 
efficient. The ionization signal strength due 10 atomic hydrogen was recorded as a function of filament lemperature and found to approximatcly double between 1860 and $1990^{\circ} \mathrm{C}$, as expected.'

\subsection{Boundary layer gases}

All chemical vapor deposition processes for diamond film growth use a mixture of gases activated by some means, such as a hot filament, if or microwave plasmas, or a name. The activated species are transported to the surface of the film, with reactions occurring in all regions, activation, transport, and film boundary layer where important surface reactions take place.

For the investigation of the boundary layer, we have used a technique that we have developed in our laboratory for combustion diagnostics. This technique makes use of a small orifice in the substrate that connects the reactor to a high vacuum chamber. The method has been demonstrated for an alr-acelylene name' and also for a gasoline-burning internal combustion engine." While the sharp reduction in collisional broadening of the spectral lines removes most of the background interference, further improvement in sensisivity and specificity can be achieved with the additton of mass-selective detection.

Whenever surface or surface-enhanced reactions are occurring and transport to the surface of reactant species is diffusion limited, there will be concentration gradients near the surface in a boundary layer. Knuth' has used hydrodynamic focusing arguments to show that cither the boundary layer or the bulk gas above it can be samples by an orifice, with the sampled region depending on the ratio of orifice throat diameter, d, to boundary layer thickness, 8. For $d<8$, the sampled gases are principally from the boundary layer. For $d>\delta$, bulk gas will be concentrated in the center of the how and can be isolated with a skimmer. Pumping constraints favor smaller orifices so the method is ideally suited for boundary layer measurements.

For orifice sampling experiments, the growth reactor described above is inserted into a stainless steel high vacuum chamber, and a quartz reactor with an orifice in its flat bottom is employed. Both quartz capillary (0.5 mm i.d.) and remoyable ceiamic nozzles have been invesugated. The former was found to be 100 fragile for practical use. A matching orifice was chemically etched in a silicon substrate to accept the nozzle outside diameter; the nozzle length is such that it extends through the subsirate and terminates exactly at the surface. There are chamber windows for optical studies of the reactants in the filament and ransport regions as welt as for observing the subsirate surface.

The region downstream of the reactor nozzle is pumped by a $450 \mathrm{~L} / \mathrm{s}$ turbomolecular pump to a pressure of about 1 micron. Thus the expanding reactor gases reach a collisionless envitonment rapidly in order 10 suspend any further reaction. A conical molecular beam skimmer forms an aperture into the high vacuum region ( $5 \times 10^{-1}$ torr) of the chamber where TOF mass speciroscupy (l meter path) is performed. Optical access exists before and after the skimmer. An electron gun permis acquisilion of survey TOF mass spectra by electron impact (EI) ionization. Suprasil entrance and exil windous exposing the ion exiracion region allow for mass resolved. UV REMPI speciroscopy. Dala acquisition is aciumplished with a $3(x) \mathrm{MHz}$ digilal oscilloscise and a personal compuler.

The $1 \%$ methane in hydrogen mixture was decomposed in the hot filament reactor and the resulting gas mixture composition followed by TOF mass spectrometry. The results are summarized in Figure 2. The boundary layer gases were extracted inrough a $0.34 \mathrm{~mm}$ diameter ceramic nozzle through the substrate. Electron impact ionization was utllized, with 70 volt elecirons. Figute $2 \mathrm{~A}$ is a TOF mass specirum with the spectrumeter evacuated (i.e., no feed gas); water and its $O H$ fragment are evident at $\mathrm{m} / 218$ and 17 , respectively. A reactor pressure of 20 torr was established for Figure $2 \mathrm{~B}$ by supplying a 100 SCCM flow of the methane hydrogen mixture; the reactor filament is still off. Methane and its El fragmenis appear along with some unidenuffied heavier impuritues. Finally, for Figure $2 \mathrm{C}$ the reactor filament was heated $101970^{\circ} \mathrm{C}$; the methane mass peaks diminish greatly, and acelylene is seen to arise at miz 26. Alomic hydrogen was also observed, and its telative abundance noted as a function of filament temperature.

\section{DISCLAIMER}

The repont was prepared ats an account of wosk sponsored by an agency of the Injted States Gusernment Nether the Unted States (iovernment nor any agenç thereof, nor any of their employees, makes any uarraniy, express or implied, or assumes any legal labaliaty os responsihility for the accuracy. completeness. or usefulness of any information. apparatus, product, or process disclosed, or represents that its use would not infringe privtely owned rights Refer ence herean to any specific commercial product. process, or service by trade name. trademark. manufacturer, or otherwise does not necessarily constitute or irnply its endorsement, recommendation, or favoring by the l/nited States Government or any agency thereof The views and opinions of authors expressed herein do not necessarily state or reflect those of the 


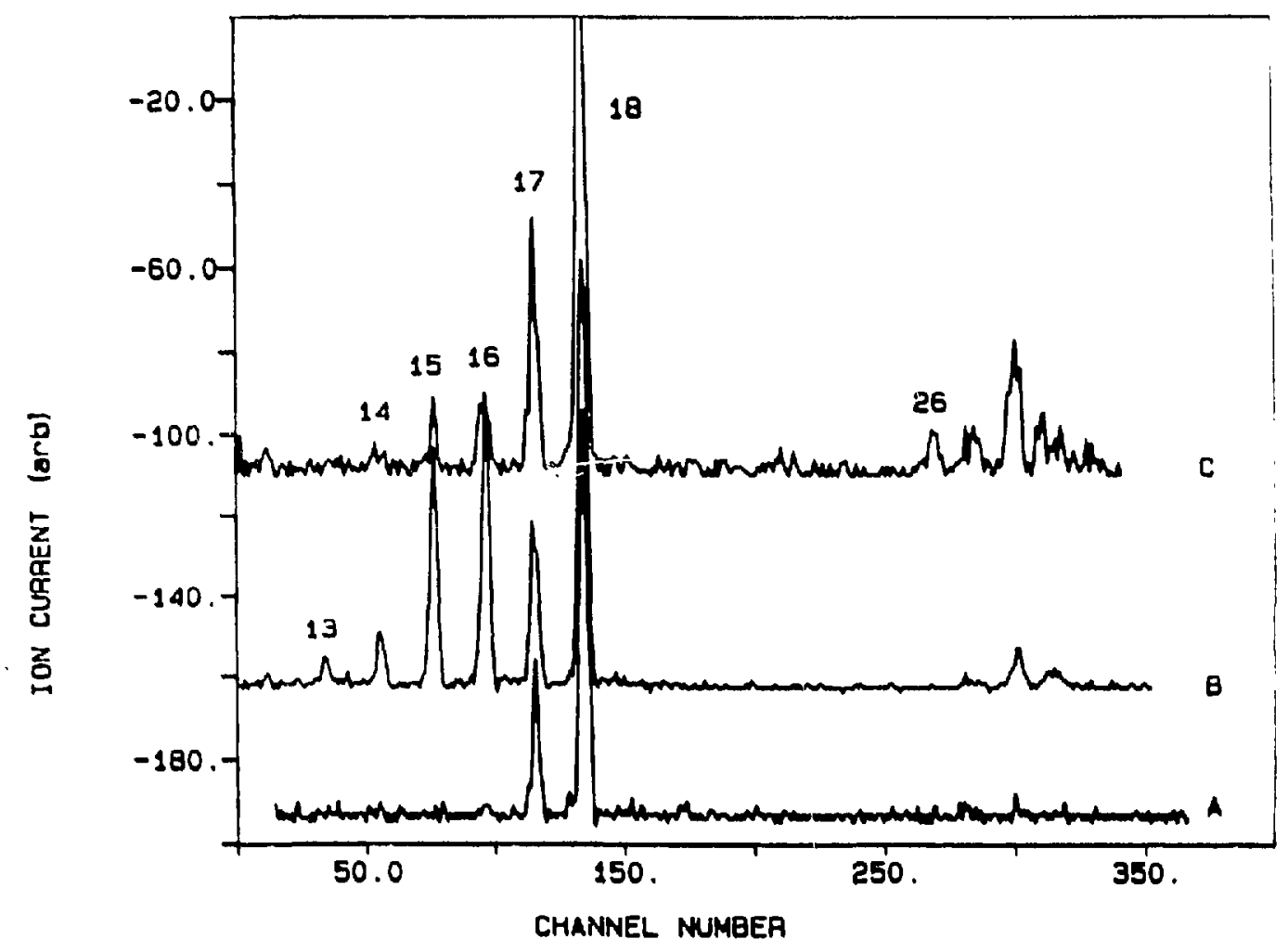

Figure 2. TOF mass spectra by through-the-substrate sampling: A) no reactant gas; B) methane/hydrogen mixture: and C) methane/hydrogen mixture decomposed at $1970^{\circ} \mathrm{C}$.

With El ionization, extensive fragmentation of methane is observed; thus eleciron ionization could potentially lcad to confusing results, indicating the presence of fragmenl species in the reacing gas mixture. For REMPI this is rir: a problem, as the uplical speciral signalure of an intermediate must be observed when the laser is seanned is, qualits it as a component of the reactor gas. For REMPI testing at room temperaturc, a surrogate muxture of nitric oxide in argon was employed; deccction of NO was accomplished via $2+2$ REMPI near $430 \mathrm{~nm}$.

\subsection{Film surface species}

The final region to be probed is the material at the surface of the growing film itself. For an understanding of grown processes, we feel that only the monolayer of material on the surface should be examined. Two interesting new approaches to probing the surface layer of materials are second-harmonic generation ${ }^{\circ}$ and sum-frequency generation.' These are optical probes of the surface that are quite sensitive to interfacial phenomena while not requiring an ultra-high vacuum environment. Sum-frequency generation is more interesting than second-harmoni. generation in that in situ vibrational spectroscopy of molecules on the surface can be performed. A tunable inirares photon 15 mixed with a visible photon at the growing film/gas interface to creale a higher frequency visible signai beam. Enhancement of the signal beam generalion occurs near resonances of species present and vibrational spectrd of molecules on the surface result as the infrared laser is scanned through molecular resonances. The second ordet 


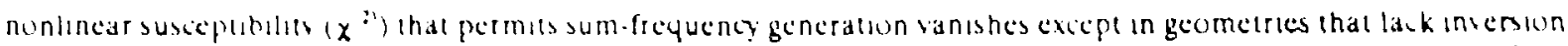

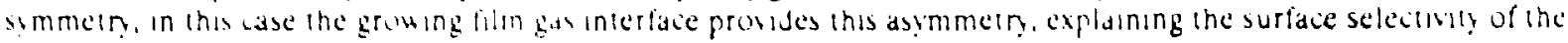
methud. Background signal trom buik malerial should be minimal.

We are regınnıng to develop a high-peak-power, picosecond-duration, tunable infrared laser source for investigation of diamond film growth. A picosecond pulsed laser is desired because low average power is necessary to prevent altering the surface chemistry with the laser itself. The most valuable spectral regions for investigation are the C.H and C.C strectining vibration regions at 2900 and $1330 \mathrm{~cm}^{-3}$, respectively. An oplical paramerric oscillator math prouslle as the nonlinear medium and a regeneratively-amplified NidYAG laser pump is in the early design stage.

\section{CONCLUSIONS}

Several tunable laser-based diagnostics are under development to probe CVD diamond film growh. The three imporlant reactor regions .. bulk gases, film boundary layer, and growing surface -- are individually under invesugation. Orifice sampling as implemented for the hot filament reactor is also dirccily applicable 10 the ox). acetylene flame growth method.

The combined information from diagnostics and materials characlerization will eventually contribute to a beller underslanding of CVD processes and could very well lead to modificallon of diamond deposition procedures. Medifications mighi be made 10 change the dominance of differene molecular species present in the vapor phase 10 optimiac malerial groulh, allernalely. It might be adsanlageous lo intreduce a new chemical species. He feel that this global approacti to invesligallng malerlals synthesis from the vapor phase is a rational strateg no maller what maleral is being groh'n.

\section{ACKNOWLEDGEMENTS}

Research sponsored by U.S. Departmeni of Energy, Office of Energy Research, under contract DE.ACO5-84OR21+00 with Martin Marietta Energy Systems, Inc.

\section{REFERENCES}

1. F. G. Celli and J. E. Butler, "Hydrogen Atom Detection in the Filament-assisted Diamond Deposition Environmenı," Appl. Phys. Letr., 54, 1031 (1989).

2. F. G. Celli, H. R. Thorsheim, M. A. Hanratly, and J. E. Butler, "Oxyen Alum Delection using Third Harmonic Generation," Applied Oprics, 29, 3135 (1990).

3. P. R. Blazewicz, W. B. Whitten, and J. M. Ramsey, "Low-level Detection of Metal Atoms by Multiphoton Ionization in a Low-pressure Flame Sampling Cell," Anal. Chem., 61, 1010 (1989).

4. W'. B. Whitten, "Supersonic Jet Sampling for Combustion Diagnosucs," Appl. Spectrosc., 40, 104 (1986).

5. E. L. Knuth, "Direct-sampling Siudies of Combustion Processes," Engine Emissions - Pollutant Formation and Measurement, G. S. Springer and D. J. Patterson, eds., pp. 319-363, Plenum, New York, 1973.

6. Y. R. Shen, "Surface Second Harmonic Generation: A New Technique for Surface Studies," Ann. Rev. Mater. Sci, R. A. Huggins, J. A. Giordmaine, and J. B. Wachiman, Jr., eds., Vol. 16, pp. 69.86, Annual Revieus, Palo Alio, CA. 1986.

7. J. H. Hunt, P. Guyot-Sionnest, and Y. R. Shen, "Observation of CH Stretch Vibrations of Monolayers of Molecules by Optical Sum Frequency Generation," Chem. Phys. Lett., 133, 189 (1987). 